\title{
Enantiomeric Separation of Sibutramine by Capillary Zone Electrophoresis
}

\author{
Gabriel Hancu, ${ }^{* a}$ Alexandra Hilochie, ${ }^{a}$ Alexandru-Robert Vlad, ${ }^{a}$ Anca Cârje ${ }^{b}$ and \\ Amelia Tero-Vescan \\ ${ }^{a}$ Department of Pharmaceutical Chemistry, ${ }^{b}$ Department of Drug Analysis and Analytical Chemistry \\ and ${ }^{~}$ Department of Biochemistry, Faculty of Pharmacy, University of Medicine and Pharmacy, \\ 540139 Tîrgu Mureş, Romania
}

\begin{abstract}
The chiral separation of sibutramine enantiomers was resolved succesfully by capillary zone electrophoresis using cyclodextrins (CDs) as chiral selectors. A complex screening of several different native and derivatized, neutral and ionized cyclodextrine derivatives was performed. The effects of buffer type, concentration and $\mathrm{pH}$, cyclodextrin type and concentration, applied voltage, capillary temperature and injection parameters on the chiral resolution were examined. The best results on a very short fused silica capillary of $30 \mathrm{~cm} \times 50 \mu \mathrm{m}$ were obtained using a $50 \mathrm{mmol} \mathrm{L}^{-1}$ phosphate buffer containing $10 \mathrm{mmol} \mathrm{L}^{-1}$ randomly methylated $\beta$-CD at a $\mathrm{pH}$ of 4.5 , $15 \mathrm{kV}$ of voltage, temperature of $15^{\circ} \mathrm{C}$, injection parameters of $30 \mathrm{mbar} \mathrm{s}^{-1}$ and ultraviolet (UV) detection at $220 \mathrm{~nm}$. The analytical performances of the optimized method were verified in terms of linearity, precision and robustness, and limit of detection and quantification were calculated.
\end{abstract}

Keywords: sibutramine, chiral separation, capillary electrophoresis, cyclodextrins

\section{Introduction}

Sibutramine $[( \pm)-1-(p$-chlorophenyl $) \alpha$-isobutyl- $N, N$ dimethyl cyclobutane methylamine hydrochloride] is an oral anorexiant structurally related to amphetamine. Sibutramine contains a chiral center in its structure, and consequently, there are two available enantiomer $(R$ and $S)$, but is marketed as a racemic mixture (Figure 1). ${ }^{1}$

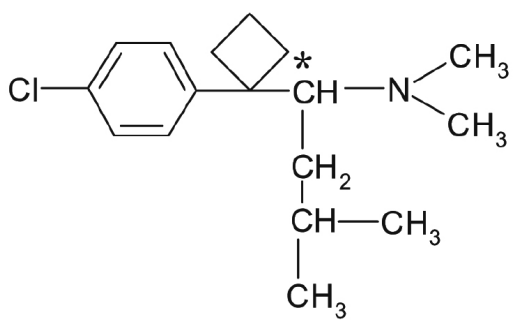

Figure 1. Chemical structure of sibutramine. The asterix denotes the chiral center.

Sibutramine is a centrally acting serotonin (5-HT) and noradrenaline (NA) reuptake inhibitor. It also inhibits dopamine reuptake but to a lesser extent, increasing the levels of these substances in synaptic clefts and helping enhance satiety. It has a distinct mechanism of action as it

*e-mail: gabriel.hancu@umftgm.ro does not influence the release of these neurotransmitters (like amphetamine), possessing a dual mode of action by enhancing satiety to decrease food intake, and enhancing thermogenesis to increase energy expenditure. ${ }^{2,3}$

Sibutramine is used in the management of obesity, being prescribed as an adjunct in the treatment of exogenous obesity along with adequate diet and exercise. ${ }^{4}$

In 2010, sibutramine was removed from the European market, based on new data from the Sibutramine Cardiovascular Outcomes Trial (SCOUT), which demonstrated an increased risk of cardiovascular events, such as stroke or heart attack. Therefore, it was concluded that any benefit brought by the use of sibutramine do not compensate the risks imposed to the patients. In the same year, the U. S. Food and Drug Administration recommended against prescription and use sibutramine based medicines and requested the withdraw of products containing this drug from the United States market. ${ }^{5}$

However, the illicit addition of sibutramine in counterfeit weight loss products has been reported, which represents a serious public health problem. ${ }^{6}$

The differences between the pharmacokinetic and pharmacological properties of the sibutramine enantiomers are well documented and demonstrated, as $R$-sibutramine decreases body weight and food uptake, while $S$-sibutramine increases body weight and food uptake. ${ }^{7}$ Also the 
sibutramine pharmacological action is related to the two active metabolites resulted by amine demethylation. The active metabolites of sibutramine also exhibit enantioselective effects, as the $R$-sibutramine metabolites have dramatically higher potency as an anorexic than the $S$-sibutramine metabolites and also $R$-sibutramine is biotransformed preferentially over $S$-sibutramine. Taking in consideration all these aspects for efficiency and safety reasons, maybe sibutramine should have been developed and used as a pure enantiomer. ${ }^{8}$

For the development of sibutramine as a chiral drug and for pharmacological and pharmacokinetic research, the enantioselective separation and determination of sibutramine is a necessity and also a challenge.

There have been reports of the chiral separation of sibutramine by high-performance liquid chromatography (HPLC) techniques, using Chiracel OD column, ${ }^{9}$ proteinbased chiral stationary phase ${ }^{10}$ or Chiralcel AGP-stationary phase column. ${ }^{11}$

Capillary electrophoresis (CE) has gained momentum lately in the chiral analysis of pharmaceutical compounds, being considered today as an alternative and also a complementary method to the more frequently used chromatographic techniques. CE advantages in chiral analysis are related to its high efficiency, low consumption of samples and reagents, short analysis time, ease of operation and, especially, to the high selectivity in choosing and changing chiral selectors. Also chiral separation by CE can be performed simply by adding the chiral selector to the buffer electrolyte. ${ }^{12}$

Only a few study using CE methods for the enantioseparation of sibutramine has been published so far using cyclodextrine derivatives as chiral selectors; ${ }^{13}$ possible correlations between $\mathrm{CE}$ and nuclear magnetic resonance (NMR) spectroscopy have been also examined. ${ }^{14}$

In this study, chiral separation of sibutramine was investigated by CE by screening different native and derivatized, neutral and ionized cyclodextrin (CD) derivatives as chiral selectors.

\section{Experimental}

\section{Instrumentation}

Separations were conducted on an Agilent $7100 \mathrm{CE}$ System (Agilent Technologies, Santa Clara, CA, USA) equipped with a diode array detector (DAD). Uncoated bare fused-silica capillary of $30 \mathrm{~cm}$ length $(22 \mathrm{~cm}$ effective length) $\times 50 \mu \mathrm{m}$ inner diameter (Agilent Technologies, Santa Clara, CA, USA) was used. Data acquisition was performed with ChemStation software (Agilent
Technologies, Santa Clara, CA, USA). The $\mathrm{pH}$ of the buffers was adjusted using a InoLab Terminal $740 \mathrm{pH}$ meter (WTW GmbH, Weilheim, Germany).

\section{Chemicals}

$R, S$-Sibutramine hydrochloride and $R$-sibutramine were purchased from Chemos $\mathrm{GmbH} \& \mathrm{Co}$. (Regenstauf, Germany). As chiral selectors, we used the following CD derivatives of research grade: native neutral $\mathrm{CD}(\alpha-\mathrm{CD}$, $\beta-\mathrm{CD}, \gamma-\mathrm{CD}$ ); derivatized neutral $\mathrm{CD}$ [hydroxypropyl- $\beta-\mathrm{CD}$, HP- $\beta-C D$; hydroxyethyl- $\beta-C D$, HE- $\beta-C D$; randomly methylated $\beta-C D$, RAMEB; heptakis(2,3,6-tri- $O$-methyl)$\beta-\mathrm{CD}$, TM- $\beta-\mathrm{CD}$ ); and anionic substituted charged CD (carboxymethyl- $\beta-\mathrm{CD}, \mathrm{CM}-\beta-\mathrm{CD}$; sulfobuthyl ether- $\beta$ CD, SBE- $\beta-C D$ ). All CDs were obtained from CycloLab Cyclodextrin Research and Development Laboratory Ltd. (Budapest, Hungary) with the exception of SBE$\beta$-CD, obtained from Captisol (La Jolla, CA, USA). All reagents used for the preparation of buffers and samples were of analytical grade: phosphoric acid, disodium hydrogen phosphate, sodium dihydrogen phosphate, sodium tetraborate, sodium hydroxide (Merck \& Co., Inc., Kenilworth, NJ, USA) and methanol (Lach-Ner, Neratovice, Czech Republic). Purified water was provided by a Milli-Q Plus water purification system (Millipore, Billerica, MA, USA).

\section{Sample preparation}

Stock solutions of sibutramine of $100 \mu \mathrm{g} \mathrm{mL}^{-1}$ were prepared in methanol and later diluted to the desired concentration. All solutions were kept in the refrigerator when not in use. The samples were introduced in the system at the anodic end of the capillary by hydrodynamic injection. All sample solutions and buffers were degassed by ultrasound for $5 \mathrm{~min}$ before use and filtered through a $0.25 \mu \mathrm{m}$ membrane filter (Agilent Technologies, Santa Clara, CA, USA).

\section{CE procedure}

Capillaries were conditioned by flushing $30 \mathrm{~min}$ with $0.1 \mathrm{~mol} \mathrm{~L}^{-1} \mathrm{NaOH}$ and $15 \mathrm{~min}$ with water. Between injections, the capillary was preconditioned for $2 \mathrm{~min}$ with the running buffer prior to each subsequent run. In the preliminary analysis, we applied some standard electrophoretic conditions for a $\mathrm{CE}$ analysis: temperature $20^{\circ} \mathrm{C}$, applied voltage $+25 \mathrm{kV}$, injection pressure $50 \mathrm{mbar}$, injection time $3 \mathrm{~s}$, sample concentration $25 \mu \mathrm{g} \mathrm{mL}{ }^{-1}$, ultraviolet (UV) detection at $220 \mathrm{~nm}$. 


\section{Enantioselectivity evaluation}

The separation factors $(\alpha)$ were calculated as the ratio of the migration times of the optical isomers and the resolution $(\mathrm{R})$ was obtained by equation 1 :

$\mathrm{R}=\frac{2\left(\mathrm{t}_{2}-\mathrm{t}_{1}\right)}{\mathrm{w}_{1}+\mathrm{w}_{2}}$

where the migration times $\left(t_{1}\right.$ and $\left.t_{2}\right)$ and the peak-widths $\left(\mathrm{w}_{1}\right.$ and $\left.\mathrm{w}_{2}\right)$ were marked for the slow and fast migrating enantiomers, respectively.

\section{Results and Discussion}

\section{Preliminary analysis}

Preliminary studies were performed in order to find the suitable background electrolyte (BGE) and $\mathrm{pH}$ for the determination. Structurally sibutramine is an amine $(\mathrm{pKa}=-8.5)$ and, consequently, can be detected in an acidic environment, where sibutramine will be positively charged. ${ }^{15}$ Several BGEs with different compositions (phosphate, borate buffers) over a wide $\mathrm{pH}$ range (2-12) were studied. The $\mathrm{pH}$ of the buffer was adjusted with $1.0 \mathrm{~mol} \mathrm{~L}^{-1}$ sodium hydroxide or $1.0 \mathrm{~mol} \mathrm{~L}^{-1}$ phosphoric acid.

The electrophoretic mobility of the analyte and the electroosmotic flow (EOF) are substantially $\mathrm{pH}$ dependent. In addition, the complexation of the analyte and the selector, as well as the stability of the complex, can be markedly affected by $\mathrm{pH}$.

Sibutramine can be detected over a $\mathrm{pH}$ range between 2.0 and 7.0; as for $\mathrm{pH}$ values higher than 7.0, no characteristic signal for the analyte was observed. The best peak shape was obtained using a phosphate BGE at a $\mathrm{pH} 4.5$.

The type and concentration of CD added to BGE is of primary importance in achieving chiral resolution. In order to find the optimum chiral selector for the enantioseparation, neutral CDs with concentrations of $10 \mathrm{mmol} \mathrm{L}^{-1}$ were dissolved in the BGE, while for charged CDs we added concentrations of $5 \mathrm{mmol} \mathrm{L}^{-1}$ to limit the increase of ionic strength, which generated high currents.

Chiral interactions were observed when using RAMEB and HP- $\beta-C D$ at $\mathrm{pH}$ values between 3.0 and 5.0, and
CM- $\beta-\mathrm{CD}$ at $\mathrm{pH}$ values between 6.0 and 7.0. All three CDs can be used for the enantioseparation of sibutramine, but there are some differences in resolution, peak shape and, especially, migration time. CM- $\beta-C D$ is an anionic CD derivative, in which the carboxyl groups are protonated (and result in an electrically neutral CD) below $\mathrm{pH} 4.0$ but dissociated (to form a negatively charged $\mathrm{CD}$ ) at $\mathrm{pH}$ above 4.0 , which will give a migration direction opposite to the EOF, resulting in longer migration times (above $10 \mathrm{~min}$ ) and broader peak shapes. RAMEB and HP- $\beta-C D$ are neutral $\mathrm{CD}$ derivatives, have no own electrophoretic mobility and will migrate in the same direction with the EOF, resulting in shorter migration times (below $5 \mathrm{~min}$ ) and sharper peak shapes.

Although CM- $\beta-C D$ gave a slightly higher resolution, RAMEB was chosen as the optimal chiral selector in this study because of the shorter analysis time and better signal-to-noise $(\mathrm{S} / \mathrm{N})$ ratio.

The preliminary results obtained for the CDs that exhibited chiral interactions with sibutramine are summarized in Table 1.

\section{Optimization of the analytical conditions}

The effect of buffer concentration was studied by varying the phosphate concentrations from 25 to $100 \mathrm{mmol} \mathrm{L}^{-1}$ at a constant $\mathrm{pH}$ of 4.5. A slight increase in the migration time and a decrease in the magnitude of EOF was observed with increasing buffer concentration. High buffer concentrations generate elevated currents, due to Joule heating. Consequently $50 \mathrm{mmol} \mathrm{L}^{-1}$ phosphate bufffer was used.

The effect of different CD concentrations (1-20 mmol L $\mathrm{L}^{-1}$ RAMEB) on the chiral resolution was investigated and it was found that has an uneven effect on the resolution. Increasing the CD concentration causes the increase of migration times, but the chiral resolution increased from 1 to $10 \mathrm{mmol} \mathrm{L}^{-1}$ and decreased beyond $15 \mathrm{mmol} \mathrm{L}^{-1}$. Thus, a concentration of $10 \mathrm{mmol} \mathrm{L}^{-1} \mathrm{RAMEB}$ was selected for the enantioseparation, as it provided a baseline separation of the two enantiomers.

The effect of voltage $(15-30 \mathrm{kV})$ on the separation was also studied. Higher voltage resulted in shorter

Table 1. Capillary electrophoresis (CE) separation data of sibutramine enantiomers using cyclodextrin (CD) as chiral selectors

\begin{tabular}{lccccc}
\hline CD derivative & $\mathrm{pH}$ & $\mathrm{t}_{1}{ }^{\mathrm{d}} / \min$ & $\mathrm{t}_{2}{ }^{\mathrm{e}} / \min$ & $\mathrm{R}^{\mathrm{f}}$ & $\alpha^{\mathrm{g}}$ \\
\hline $10 \mathrm{mmol} \mathrm{L}^{-1} \mathrm{HP}-\beta-\mathrm{CD}^{\mathrm{a}}$ & 4.5 & 3.9 & 4.0 & 1.1 & 1.02 \\
$10 \mathrm{mmol} \mathrm{L}^{-1} \mathrm{RAMEB}^{\mathrm{b}}$ & 4.5 & 4.0 & 4.2 & 1.5 & 1.05 \\
$5 \mathrm{mmol} \mathrm{L}^{-1} \mathrm{CM}-\beta-\mathrm{CD}^{\mathrm{c}}$ & 7.0 & 11.2 & 11.7 & 1.8 & 1.04 \\
\hline
\end{tabular}

${ }^{\mathrm{a}}$ Hydroxypropyl- $\beta-\mathrm{CD}$; ${ }^{\mathrm{b}}$ randomly methylated $\beta-\mathrm{CD} ;{ }^{\mathrm{c}}$ carboxymethyl- $\beta-\mathrm{CD} ;{ }^{\mathrm{d}}$ migration time of enantiomer 1 and ${ }^{\mathrm{e}}$ of enantiomer 2 ; ${ }^{\mathrm{f}}$ resolution; ${ }^{\mathrm{g}} \mathrm{Separation}$ factor. Background electrolyte (BGE) $25 \mathrm{mmol} \mathrm{L}^{-1}$ phosphate, applied voltage $+25 \mathrm{kV}$, system temperature of $20^{\circ} \mathrm{C}$. 
migration times, but also in a slight decrease in chiral resolution. A voltage of $15 \mathrm{kV}$ was selected as optimal for the separation.

The effect of capillary temperature $\left(15-25{ }^{\circ} \mathrm{C}\right)$ was studied under the chosen buffer condition. When temperature was increased, a decrease in both migration time and chiral resolution occurred. Thus, best results were obtained when capillary temperature was set at $15^{\circ} \mathrm{C}$.

The amount of sample introduced in the capillary influences sensitivity as well as resolution. Sample injection time (1-5 s) and pressure (30-50 mbar) were varied in order to achieve lower detection limit without affecting the peak shape and resolution. Considering all these parameters, an injection pressure of $30 \mathrm{mbar}$ and an injection time of $1 \mathrm{~s}$ was selected as optimal.

From the above experiments, the optimal conditions for the enantioseparation of sibutramine were: $50 \mathrm{mmol} \mathrm{L}^{-1}$ phosphate running buffer, $\mathrm{pH} 4.5,10 \mathrm{mmol} \mathrm{L}^{-1}$ RAMEB as chiral selector, applied voltage $15 \mathrm{kV}$, capillary temperature of $15^{\circ} \mathrm{C}$, injection pressure/time $30 \mathrm{mbar} \mathrm{s}^{-1}$ and detection wavelength $220 \mathrm{~nm}$.

The migration order of the two enantiomers was determined by injecting a solution of the racemate enriched with the pure enantiomer separately. The migration order was determined to be $S$-sibutramine followed by $R$-sibutramine.

The faster migration of the $S$-sibutramine indicates that this enantiomer have weaker interaction with the CDs, while the interaction of $R$-sibutramine is stronger.

Applying the optimized conditions, we obtained a chiral resolution of 1.80 and a separation factor of 1.05 , the enantiomers migrating in less than $5 \mathrm{~min}$. A typical electropherogram obtained under the optimized conditions is presented in Figure 2.

\section{Analytical performances}

Calibration curves were constructed by plotting the peak area (y) vs. analyte concentration (x) in $\mu \mathrm{g} \mathrm{mL}^{-1}$. Six standard solutions containing 5-100 $\mu \mathrm{g} \mathrm{mL}^{-1}$ racemic mixture of sibutramine were analyzed and the analysis was performed in triplicate. The linear regression equations are summarized in Table 2.

The limits of detection (LOD) and quantification (LOQ) were determined as the amount of the introduced sample to yield a signal-noise ratio of 3 to 10 (Table 2).

Precision of the method was evaluated with regard for both intra-day and inter-day precision. The intra-day precision was evaluated by introducing a racemic mixture of sibutramine at three different concentration levels $\left(10,25\right.$ and $\left.50 \mu \mathrm{g} \mathrm{mL}^{-1}\right)$ six times on the same day, while the inter-day precision was tested by introducing three concentration levels $\left(10,25\right.$ and $\left.50 \mu \mathrm{g} \mathrm{mL}^{-1}\right)$ of a racemic mixture six times for three consecutive days. Good precision values were obtained evidenced from the relative standard deviation (RSD) for migration time and peak area presented in Table 3.

Robustness tests were carried out by modifying the electrophoretic conditions in order to investigate the reliability of the results when experimental parameters were slightly changed. The variation of the buffer concentration by $\pm 5 \mathrm{mmol} \mathrm{L}^{-1}, \mathrm{pH}$ of the running buffer by \pm 0.5 and the applied voltage by $\pm 2 \mathrm{kV}$ did not have significant effect on the results, with RSD values under $2 \%$.

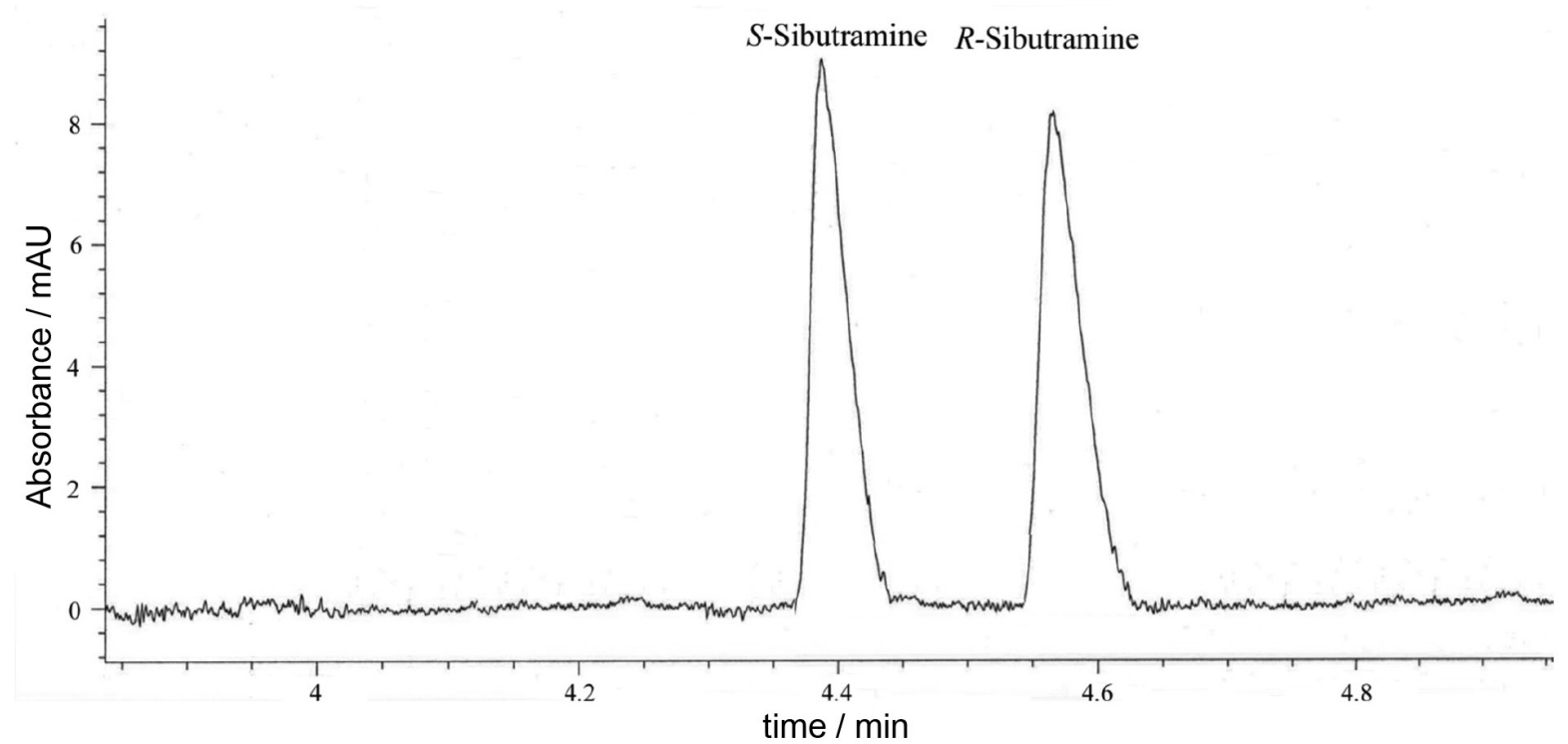

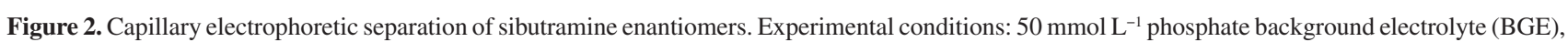
chiral selector $10 \mathrm{mmol} \mathrm{L}^{-1}$ randomly methylated $\beta$-CD (RAMEB), $\mathrm{pH} 4.5$, voltage $+15 \mathrm{kV}$, temperature $15^{\circ} \mathrm{C}$, hydrodynamic injection 30 mbar s${ }^{-1}$, sample concentration $10 \mu \mathrm{g} \mathrm{mL}^{-1}$, ultraviolet (UV) detection $220 \mathrm{~nm}$. 
Table 2. Calibration data, limit of detection (LOD) and limit of quantification (LOQ) values for sibutramine chiral separation

\begin{tabular}{|c|c|c|c|c|}
\hline Enantiomer & Regression equation & Correlation coefficient & $\mathrm{LOD} /\left(\mu \mathrm{g} \mathrm{mL} L^{-1}\right)$ & $\mathrm{LOQ} /\left(\mu \mathrm{g} \mathrm{mL}^{-1}\right)$ \\
\hline$S$-Sibutramine & $y=0.9321 x+7.5365$ & 0.9909 & 3.69 & 12.30 \\
\hline$R$-Sibutramine & $y=0.8776 x+7.0886$ & 0.9927 & 3.42 & 11.40 \\
\hline
\end{tabular}

Table 3. Intra-day and inter-day reproductibility data for repeated introductions of different concentrations of racemic sibutramine standard

\begin{tabular}{|c|c|c|c|c|}
\hline \multirow{3}{*}{$\begin{array}{l}\text { Factor concentration / } \\
\left(\mu \mathrm{gL}^{-1}\right)\end{array}$} & \multicolumn{4}{|c|}{ Relative standard deviation / \% } \\
\hline & \multicolumn{2}{|c|}{ Migration time / $\min$} & \multicolumn{2}{|c|}{ Peak area } \\
\hline & $S$-Sibutramine & $R$-Sibutramine & $S$-Sibutramine & $R$-Sibutramine \\
\hline \multicolumn{5}{|c|}{ Intra-day precision $(n=6)$} \\
\hline 10 & 0.08 & 0.13 & 0.98 & 1.05 \\
\hline 25 & 0.03 & 0.08 & 0.74 & 0.90 \\
\hline 50 & 0.04 & 0.09 & 0.71 & 0.85 \\
\hline \multicolumn{5}{|c|}{ Inter-day precision $(\mathrm{n}=18)$} \\
\hline 10 & 0.80 & 0.95 & 1.77 & 2.00 \\
\hline 25 & 0.75 & 0.90 & 1.68 & 1.90 \\
\hline 50 & 0.72 & 0.88 & 1.70 & 1.82 \\
\hline
\end{tabular}

\section{Conclusions}

A simple, cost effective and rapid CE method has been developed for the enantioselective separation of sibutramine enantiomers, resulting in baseline separation of the two enantiomers with sharp peaks and short analysis time.

The effects on the chiral separation of sibutramine enantiomers of experimental parameters, such as type and concentration of chiral selectors, type and concentration of the BGE, the applied voltage and the capillary temperature, were systematically investigated. $\mathrm{CD}$ type and concentration, $\mathrm{pH}$ value of the BGE and capillary temperature had a strong influence on the efficiency of the chiral separation. The changes in the concentration of the CDs and in the $\mathrm{pH}$ of the BGE showed uneven effect on the resolution of the optical isomers.

The method is advantageous if compared with the more frequently described and used HPLC methods, because it does not require expensive chiral columns or large amounts of solvents as mobile phase.

\section{Acknowledgments}

Our work was supported with a project funded through Internal Research Grants by the University of Medicine and Pharmacy of Tîrgu Mureş, Romania (grant contract for execution of research projects No. 22).

\section{References}

1. Block, J. H.; Beale, J. M.; Organic Medicinal and Pharmaceutical Chemistry, $12^{\text {th }}$ ed.; Lippincot Williams \& Wilkins: Philadelphia, 2011.
2. Heal, D. J.; Aspley, S.; Prow, M. R.; Jackson, H. C.; Martin, K. F.; Cheetham, S. C.; Br. J. Pharmacol. 1998, 125, 201.

3. Araujo, J. R.; Martel, F.; Curr. Neuropharmacol. 2012, $10,49$.

4. Finer, N.; Int. J. Obes. 2002, 26, 29.

5. Tyczynski, J. E.; Oleske, D. M.; Klingman, D.; Ferrufino, C. P.; Lee, W. C.; Drug Saf. 2012, 35, 629.

6. Csupor, D.; Boros, K.; Dankó, B.; Veres, K.; Szendrei, K.; Hohmann, J.; Pharmazie 2013, 68, 15.

7. Bodhankar, S. L.; Thakurdesai, P. A.; Singhal, S.; Gaur, V.; Indian J. Physiol. Pharmacol. 2007, 51, 175.

8. Glick, S. D.; Haskew, R. E.; Maisonneuve, I. M.; Carlson, J. N.; Jerussi, T. P.; Eur. J. Pharmacol. 2000, 397, 93.

9. Radhakrishna, T.; Narayana, C. L.; Rao, D. S.; Vyas, K.; Reddy, G. O.; J. Pharm. Biomed. Anal. 2000, 22, 627.

10. Singh, A. K.; Pedro, L. G.; Gomes, F. P.; Yano, H. M.; Auricchio, M. T.; Kedor-Hackmann, E. R.; Santoro, M. I.; J. AOAC Int. 2008, 91, 572 .

11. Kang, W.; Bae, K.; Noh, K.; J. Pharm. Biomed. Anal. 2010, 51, 264.

12. Suntornsuk, L.; Anal. Bioanal. Chem. 2010, 398, 29.

13. Zhu, H.; Wu, E.; Chen, J.; Men, C.; Jang, Y. S.; Kang, W.; Choi, J. K.; Lee, W.; Kang, J. S.; Bull. Korean Chem. Soc. 2010, 31, 1496.

14. Lee, Y. J.; Choi, S.; Lee, J.; Nguyen, N. T.; Lee, K.; Kang, J. S.; Mar, W.; Kim, K. H.; Arch. Pharm. Sci. Res. 2012, 35, 671.

15. Carvalho, J. M.; da Silva, A. R.; da Cunha, A. L. M. C.; Aucelio, R. Q.; Alberti, A. L. M.; Leandro, K. C.; Quim. Nova 2012, 35, 988.

Submitted: October 21, 2015

Published online: December 18, 2015 